\title{
PRESCRIPTION AUDIT IN OUTPATIENT DEPARTMENTS OF TERTIARY CARE HOSPITALS; FACTS AND RECOMMENDATIONS
}

\author{
Muhammad Wasiullah Khan, Saleh Khurshied, Nawal Khurshid*, Rafay Iqbal, M Azeem Khizer**, Hammad Ahmed \\ Army Medical College/National University of Medical Sciences (NUMS) Rawalpindi Pakistan, *Pakistan Institute of Medical Sciences, Islamabad Pakistan, \\ **Armed Forces Institute of Ophthalmology/National University of Medical Sciences (NUMS) Rawalpindi Pakistan
}

\begin{abstract}
Objective: To evaluate written prescriptions according to a checklist based on WHO guidelines (prescription audit). To compare prescriptions of senior and junior physicians and to provide data and recommendations.

Study Design: Cross-sectional, analytic study.

Place and Duration of Study: Pak Emirates Military Hospital, and Combined Military Hospital, Rawalpindi Pakistan, from March to Aug 2018.

Methodology: A total of 205 prescriptions using convenient sampling technique were analyzed according to a checklist based on WHO guidelines for standard prescription writing. Data was analyzed using SPSS-22.

Results: Out of total 205 prescriptions, 83 (40\%) prescriptions belong to senior and $122(60 \%)$ to junior physicians. 50 (25\%) prescriptions lacked patient name, 49 (24\%) lacked age. Gender was mentioned in only 117 (57\%) prescriptions. Date, diagnosis and dosage of drug were written in $170(83 \%), 172(84 \%)$ and $177(86 \%)$ respectively while dosage form and route of administration were mentioned in $144(70 \%)$ and $102(50 \%)$ respectively. Generic name was written in only $75(37 \%)$ prescriptions. Name and stamp of the doctor were available on $135(66 \%)$ and $125(61 \%)$ prescriptions respectively. A statistically significant association was observed between senior and junior physicians in terms of error in name of patient and dosage form $(p=0.002$ $\& 0.005$ respectively).

Conclusions: Prescriptions were mainly deficient in the generic names of drugs. Route of administration was missing in half of the prescriptions. None of the parameters was totally accurate. Prescriptions from junior physicians had more errors.
\end{abstract}

Keywords: Audit, Drug, Outpatient department, Prescription.

This is an Open Access article distributed under the terms of the Creative Commons Attribution License (http://creativecommons.org/licenses/by/4.0), which permits unrestricted use, distribution, and reproduction in any medium, provided the original work is properly cited.

\section{INTRODUCTION}

Audit" is a Latin word, transferred to the English vocabulary "audit" takes on a meaning of "an official inspection of an organization's accounts, typically by an independent body"1. An 'audit' is defined as 'the review and the evaluation of the health care procedures and documentation for the purpose of comparing the quality of care which is provided, with the accepted standards ${ }^{2}$. To measure the efficacy of prescriptions the best choice is to audit. A prescription audit provides the most detailed and complete overview and idea regarding the performance of a physician with respect to prescription writing checked as per checklist of parameters. Prescription audit is a type of audit which observes, assesses and at the end provides necessary information and recommendations for modifications or changes in the physician's practice of prescribing medicines $^{3}$. A considerable amount of literature addresses the effectiveness of audits and reports different resu1 ts $^{4}$. Prescribing errors can double patients' length of hospital stay and cost of care, and increasing mortality

Correspondence: Dr Muhammad Wasiullah Khan, Department of Pharmacology, Army Medical College Rawalpindi Pakistan

Received: 02 May 2019; revised received: 15 Jul 2019; accepted: 24 Jul 2019 rate $^{5}$. With all types of medication, hospital prescribing errors are common ${ }^{6}$. Although individual factors such as knowledge and expertise played a role in prescribing mistakes, there were many perceived interrelated factors contributing to error?

To be a good clinician one should always review one's daily work accuracy and the outcome of their diagnosis and treatment. This activity of reviewing one's own progress is also an audit. A medical audit is a type of audit and is defined as evaluating the quality of medical care by analyzing previous records retrospectively ${ }^{8}$.

Rational drug use stresses that a patient should have access to the most appropriate and best medication as per demand and the doses should meet their individual requirement and should be cost effective for them and others 9 . Prescription auditing has a huge potential to promote the rational usages of drugs and essential medicine. Essential medicines are among the most important tools required to improve and maintain hea1th. Prescription audit can help us identify and promote good practice, improve professional practice and maintain quality standards, support learning and development of staff and organizations, identify and abolish poor practices, identify and eliminate wastage 
due to faulty prescriptions, promote working with multidisciplinary teams, allocate resources (financial and human) for betterment of patients and develop opportunities to present findings with relevant faculty and facilitate shared learning ${ }^{10}$.

Medicines are one of the most cost-effective health interventions. Billions of people use medicine every year but they can only be effective if used appropriately but there is evidence that more than half of all medicines are not used appropriately and this inappropriate use endangers lives of patients and causes wastage of their money. Inappropriate prescriptions resulting in inappropriate use of medicines is a global problem and results in serious consequences for patients in terms of poor health outcomes, increased adverse drug effects, antimicrobial resistance, spread of blood-borne infections in terms of non-sterile injections, and thus a waste of limited health resources. Prescription audit can help reduce many of these sources of wastage.

The rationale of our study was to observe different types of Prescription Audit parameters \& evaluate the data of audit from different departments according to different parameters in a checklist based on WHO and $\mathrm{NABH}$ guidelines and to compare results between senior and junior physicians. To provide data and recommendations for the improvement of prescription writing and to minimize errors in prescription writing and provide a database for future comparison.

\section{METHODOLOGY}

This was a descriptive cross-sectional study carried out in the OPDs of Military Hospital and Combined Military Hospital, Rawalpindi, Pakistan from March to August 2018 after procuringa formal ethics clearance certificate from Army Medical College, Rawalpindi, ethics review committee. A total of 205 prescriptions were analyzed by the non-probability convenience sampling technique according to a checklist which contained 17 parameters based on WHO and NABH guidelines. Physicians were divided into senior physicians (include consultants and specialist) and junior physicians (house officers post graduate trainees and medical officers) A written informed consent was taken from patients before analyzing their prescriptions, those who didn't consent were excluded from the study. After data collection it was analyzed by SPSS-22. Frequencies and percentages were calculated for descriptive statistics and were tabulated. Chisquare test was applied where required. A $p$-value of $\leq 0.05$ was considered as statistically significant.

\section{RESULTS}

A total of 205 prescriptions were assessed, 83 $(40 \%)$ prescriptions were written by senior physicians and $122(60 \%)$ were written by junior physicians. The demographic variables of participants showed that $7.7 \%$ patients were below 20 years of age, $22.8 \%$ were between 21-40 years of age and 69.5\% were above 40 years of age. Total number of males were $138(67.3 \%)$ while females were $67(32.7 \%)$ among total participants. For the audit, prescriptions from different OPDs were assessed for 17 parameters on a checklist and the

Table-I: Prescription audit checklist.

\begin{tabular}{l|c|c|c}
\hline $\begin{array}{l}\text { Parameter of } \\
\text { Prescription Audit }\end{array}$ & $\begin{array}{c}\text { Yes } \\
\mathbf{n}(\%)\end{array}$ & $\begin{array}{c}\text { No } \\
\mathbf{n}(\mathbf{0})\end{array}$ & $\begin{array}{c}\text { N/A } \\
\mathbf{n}(\mathbf{\%})\end{array}$ \\
\hline $\begin{array}{l}\text { Name of patient } \\
\text { mentioned }\end{array}$ & $155(75)$ & $50(25)$ & - \\
\hline Age of patient & $156(76)$ & $49(24)$ & - \\
\hline Date & $170(83)$ & $35(17)$ & - \\
\hline Diagnosis & $165(80)$ & $40(20)$ & - \\
\hline Gender of patient & $149(73)$ & $56(27)$ & - \\
\hline Dose of drug & $177(86)$ & $28(14)$ & - \\
\hline Dosage form & $144(70)$ & $61(30)$ & - \\
\hline $\begin{array}{l}\text { Route of } \\
\text { administration }\end{array}$ & $102(50)$ & $103(50)$ & - \\
\hline Duration of treatment & $156(76)$ & $49(24)$ & - \\
\hline $\begin{array}{l}\text { Frequency of drug } \\
\text { intake }\end{array}$ & $160(78)$ & $45(22)$ & - \\
\hline $\begin{array}{l}\text { Generic name along } \\
\text { with brand name }\end{array}$ & $44(22)$ & $161(78)$ & - \\
\hline Known allergy & $23(11)$ & $3(1)$ & $179(88)$ \\
\hline $\begin{array}{l}\text { Non-standard } \\
\text { abbreviations used }\end{array}$ & $6(3)$ & - & $199(97)$ \\
\hline Drug interaction & $2(1)$ & - & $203(99)$ \\
\hline Food interaction & - & - & $205(100)$ \\
\hline $\begin{array}{l}\text { Name and stamp of } \\
\text { doctor }\end{array}$ & $135(6)$ & $70(34)$ & - \\
\hline Signature of doctor & $148(72)$ & $57(28)$ & - \\
\hline & & & \\
\hline
\end{tabular}

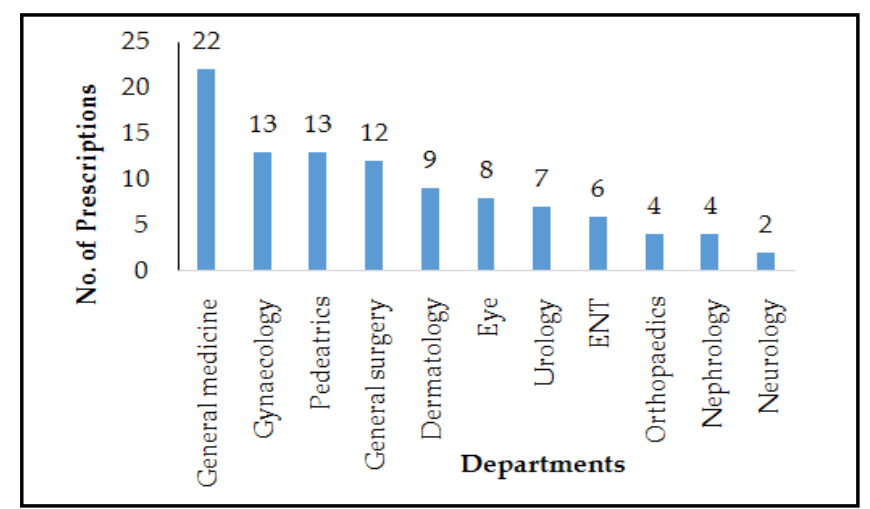

Figure-1: Number of prescriptions from different departments. 
results are shown in table-I.

Data collected from various OPDs is shown in figure and it was found that most of the prescriptions were collected from the department of general medicine $45(22 \%)$, followed by Gynecology and Pediatrics with 27 (13\%) from each department.

When prescription errors of senior physicians were compared with junior physicians (table-II) it was found that there was statistically significant association between them with respect to name of patient and dosage of drug ( $p=0.002 \& 0.005$ respectively) which showed that these errors were significantly more in prescriptions of junior physicians as compared to senior physicians.
Potharaju et al ${ }^{15}$ found in their study that about 31 percent of the prescriptions contained four or more drugs which they justified as irrational prescriptions. One way by which this practice of polypharmacy might be controlled to some extent is to establish Standard Treatment Guidelines, at least for the diseases endemic to where the hospital is located, and then by comparing with the STGs, these prescriptions could be justified or categorized as irrational. Injudicious use of antibiotics, the prescription of which is one of WHO's core prescribing indicators, also makes for inefficient prescriptions and leads to antibiotic resistance. It is also worth noting that the majority of prescriptions in our study did not mention the generic name of the drug, whereas WHO lists drugs prescribed by generic

Table-II: Comparison of consultants versus junior doctors' prescribing errors.

\begin{tabular}{|c|c|c|c|c|c|}
\hline \multirow{2}{*}{ Parameter of Prescription Audit } & \multicolumn{2}{|c|}{ Consultants $(\mathrm{n}=83)$} & \multicolumn{2}{|c|}{ PG-Trainees, $(n=122)$} & \multirow{2}{*}{$p$-value } \\
\hline & Yes, n (\%) & No, $\mathrm{n}(\%)$ & Yes, n (\%) & No, $n(\%)$ & \\
\hline Name of patient & $72(87)$ & $11(13)$ & $83(68)$ & $39(32)$ & 0.002 \\
\hline Age of patient & $65(78)$ & $18(22)$ & $91(75)$ & $31(25)$ & 0.540 \\
\hline Date & $70(84)$ & $13(16)$ & $100(82)$ & $22(12)$ & 0.658 \\
\hline Diagnosis & $70(84)$ & $13(16)$ & $95(78)$ & $27(22)$ & 0.251 \\
\hline Gender of patient & $61(73)$ & $22(27)$ & $88(72)$ & $34(28)$ & 0.830 \\
\hline Dose of drug & $78(94)$ & $5(6)$ & $99(81)$ & $23(19)$ & 0.009 \\
\hline Dosage form & $59(71)$ & $24(29)$ & $85(70)$ & $37(30)$ & 0.828 \\
\hline Route of administration & $37(45)$ & $46(55)$ & $65(53)$ & $57(47)$ & 0.221 \\
\hline Duration of treatment & $62(75)$ & $21(25)$ & $94(77)$ & $28(23)$ & 0.699 \\
\hline Frequency of drug intake & $67(81)$ & $16(19)$ & $93(76)$ & $29(24)$ & 0.445 \\
\hline Generic name along with brand name & $15(18)$ & $68(72)$ & $29(21)$ & $93(79)$ & 0.329 \\
\hline Known allergy & $20(24)$ & - & $6(5)$ & - & - \\
\hline Non-standard abbreviations used & $2(2)$ & - & $4(3)$ & - & - \\
\hline Drug interaction & $2(2)$ & - & - & - & - \\
\hline Food interaction & - & - & - & - & - \\
\hline Name and stamp of doctor & $56(67)$ & $27(33)$ & $79(65)$ & $43(35)$ & 0.687 \\
\hline Signature of doctor & $65(78)$ & $18(22)$ & $83(68)$ & $39(32)$ & 0.107 \\
\hline
\end{tabular}

\section{DISCUSSION}

Our study has audited prescriptions based on standard checklists proposed by the WHO and NABH guidelines ${ }^{11,12}$. Although not outlined in our study and somewhat subjective, it is worth noting that "legibility" is also an integral part of a high quality prescription. Saha et $\mathrm{l}^{13}$ found that in their study only $50.90 \%$ of the prescriptions were found to be clearly legible, $35.70 \%$ were legible with effort and $13.30 \%$ were totally illegible according to the pre-defined standards of legibility set by them. However, various studies show the benefit of electronic prescriptions to reduce such errors ${ }^{14}$. Writing the drug name in big capital letters might also be a cheaper and easier alternative to overcome the obstacle of legibility. names as one of its core indicators, and recommends that $100 \%$ of the drugs should be prescribed by their generic names for optimal results ${ }^{16}$.

It is particularly dismal to find that in our study, even these most basic parameters of an efficient prescription were not found in $100 \%$ of the prescriptions analyzed. This seems to be a geographically broader problem than one might think, as one study in India found that only 15\% prescriptions at St. Peters Institute of Pharmaceutical Sciences, Vidyanagar, Andhra Pradesh, noted the age of the patients ${ }^{17}$. Regarding age, however, our numbers are more promising when compared to a study done in Karachi in a dental teaching hospital by Wali et al 18 who found that only $42 \%$ of the prescriptions recorded the age of the patients. Reiterating the importance of electronic prescriptions, a study 
by Ahsan et al found that the prescriptions contained all the data that is part of the superscription and that was attributed to a computerized registration and printing system ${ }^{19}$. As an alternative, this problem can also be overcome to some extent by using hospital registration pads containing all the required fields and making sure that all those fields are filled in every prescription, which is exactly what Kumari et al found in their study $^{20}$.

A study found that $17.7 \%, 17.3 \%$ and $100 \%$ of the prescriptions were lacking in doctor's name, designation and registration number respectively ${ }^{21}$. A total of $2,660(75.0 \%)$ combined prescription errors were found to have one form of error or the other; illegitimacy 1,388 (52.18\%), omission 1,221 (45.90\%), wrong dose 51 $(1.92 \%)$ and no error of style was detected. Life-threatening errors were low (1.1-2.2\%). Errors were found more commonly among junior doctors 22 similar to our findings in terms of name of patient and dosage of drug. A study by Ajemigbetse et al ${ }^{23}$, found lack of mentioning of duration of therapy and patient age were the most common prescription errors made as were in our study.

So, it is evident from our study and the ones which have been referenced here that prescriptions these days, whether made manually, electronically, or on standardized hospital pads, are far from perfect. A "perfect prescription" itself is very subjective, which might be the reason why some doctors write more complete prescriptions than others as the standards for perfection differ from one individual to another. However, one way by which this subjectivity could be turned into objectivity is for each hospital to adopt one of the many checklists for good prescriptions available by regulatory bodies like the $\mathrm{WHO}$, and having each doctor of the hospital abide by that checklist. Not only will this ensure completeness of prescriptions, but it will also lead to better health care for the patients, reduce polypharmacy and ensure a uniform standard of care for patients seeing more than one doctor.

\section{RECOMMENDATIONS}

Based on our results and WHO good prescription writing guidelines, following are the recommendations to reduce the errors in prescription writing and improve the efficiency of hand written prescription.

1. Write all drugs in capitals ensuring correct spelling, dose, route of administration and frequency.

2. Complete all fields on the front of the prescription card legibly.
3. Document any change in the prescription card in clinical notes.

4. Prescribe only when necessary and consider benefits vs. risks.

5. Prescribe within limits of competence.

All doctors to go through their current clients' medication cards and ensure any gaps filled and errors corrected.

Audit report to be kept in audit folder as a reference for any rotating doctor to repeat the audit every six months in the services.

1. Define the patient's problem.

2. Specify the therapeutic objective.

3. Verify whether your P-treatment is suitable for this patient or not.

4. Give information, instructions and warnings.

5. Monitor the treatment and stopping when necessary.

6. Evidence based prescribing.

7. Using prescribing formularies.

8. Keeping up-to-date and following clinical guidelines where available.

\section{CONCLUSION}

Prescriptions were mainly deficient in the generic names of drugs. Route of administration was missing in half of the prescriptions. Age and gender was also missing from many prescriptions. Thus written prescriptions are predisposed to deficiencies and mistakes. None of the parameters was totally accurate, all had some deficiencies and thus the prescriptions were not efficient enough and there were many errors. When prescriptions of senior and junior physicians were compared it was observed that prescriptions of junior physicians have statistically significant error in terms of name of patient and dosage form.

\section{CONFLICT OF INTEREST}

This study has no conflict of interest to be declared by any author.

\section{REFERENCES}

1. Availablefrom: http://www.oxforddictionaries.com/definition /english/audit.

2. Srishyla M, Mahesh K, Nagarani M, Mary C, Andrade C, Venkataraman B. Prescription audit in an Indian hospital setting using the DDD (Defined Daily Dose) concept. Indian Journal of Pharmacol 1994; 26(1): 23-8.

3. Curtis P. Medical audit in general practice. J R Coll Gen Pract 1974; 24(146): 607-11. 
4. Brubakk K, Vist GE, Bukholm G. A systematic review of hospital accreditation: the challenges of measuring complex intervention effects. BMC Health Serv Res 2015; 15(1): 280-315.

5. Ivers NM, Sales A, Colquhoun H. No more 'business as usual' with audit and feedback interventions: towards an agenda for a reinvigorated intervention. Implement Sci 2014; 9(1): 14-20.

6. Elliott RA, Campbell F, Jankovic D, James MS, Kaltenthaler E, Wong R, et al. Prevalence and economic burden of medication errors in the NHS in England. Policy Research Unit in Economic Evaluation of Health \& Care Interventions (EEPRU), 2018.

7. Ryan C, Ross S, Davey P, Duncan EM, Francis JJ, Fielding S, et al. Prevalence and causes of prescribing errors: the prescribing outcomes for trainee doctors engaged in clinical training (PROTECT) study. PLoS One 2014; 9(1): e79802.

8. Joshi SK. Quality control study. In: joshi sk, quality management in hospitals. $2^{\text {nd }}$ Jaypee Brothers; 2008: 50-57.

9. Hussain S, Parveen Z, Gupta S, Kumar D, Gupta R, Thakur S. A study of prescription auditing in rural health care setting of north India. Int J Med Sci Public Health 2016; 5(6): 2461-65.

10. Hepler CD, Strand LM. Opportunities and responsibilities in pharmaceutical care. Am J Hosp Pharm 1990; 47(3): 533-43.

11. Promoting rational use of medicines: core components. WHO Policy Perspectives on Medicines, number 5. Geneva, World Health Organization, 2002.

12. Kandula PK, Rao SB, Sangeetha K. A study of prescription audit in outpatient department of a tertiary care teaching hospital in India: an observational study. J Drug Deliv Ther 2017; 7(3): 92-97.

13. Saha A, Bhattacharjya H, Sengupta B, Debbarma R. Prescription audit in outpatient department of a teaching hospital of North East India. Int J Res Med Sci 2018; 6(4): 1241-47.

14. Albarrak AI, Rashidi EA, Fatani RK, Ageel SI, Mohammed R. Assessment of legibility and completeness of handwritten and electronic prescriptions. Saudi Pharm J 2014; 22(6): 522-27.

15. Potharaju SH, Kabra GS. Prescription audit of outpatient attendees of secondary level government hospitals in Maharashtra. Indian J Pharmacol 2011; 43(2): 150-56.

16. World Health Organization. Geneva: World Health Organization; 1993. How to investigate drug use in health facilities, selected drug use indicators, WHO/DAP/93.1; p. 10. Available from: https://www.who.int/medicines/publications/how-toinvestigate_drug-use/en/

17. Pavani V. Study of prescribing pattern for evaluation of rational drug therapy in Warangal. Ind J Pharm Pract 2011; 4(4): 77-79.

18. Wali A, Ali A, Siddiqui TM, Jafri H. Assessing prescription writing skills of house officers in dental teaching hospitals of Karachi, Pakistan. World J Dentistry 2012; 3(4): 294-96.

19. Ahsan M, Shaifali I, Mallick AK, Singh HK, Verma S, Shekhar A. Prescription auditing based on World Health Organization (WHO) prescribing indicators in a teaching hospital in North India. Int J Med Res Rev 2016; 4(10): 1847-52.

20. Kumari S, Haider S, Kashyap V, Singh SB. A study on pattern of prescription writing practices at Rajendra Institute of Medical Sciences, Ranchi. Indian J Prev Soc Med 2014; 45(1): 24-28.

21. Acharya HR, Barvaliya JM, Paliwal NP, Tripathi CB. Prescription audit in outpatient departments of a tertiary care teaching hospital: A cross-sectional study. Euro J Pharma Med Res 2017; 4(3): 372-79.

22. Babatunde KM, Akinbodewa AA, Akinboye AO, Adejumo AO. Prevalence and pattern of prescription errors in a Nigerian kidney hospital. Ghana Med J 2016; 50(4): 233-37.

23. Ajemigbitse AA, Omole MK, Ezike NC, Erhun WO. Assessment of the knowledge and attitudes of intern doctors to medication prescribing errors in a Nigeria tertiary hospital. J Basic Clin Pharm 2014; 5(1): 7-14. 